\title{
VARIANCE IN A SECOND LANGUAGE PRONUNCIATION QUALITY
}

The study assessed the relation between the overall degree of perceived foreign accent in non-natives' English speech and a variety of factors. Five native speakers of English were asked to auditorily evaluate the samples of free English speech produced by each of 99 non-native talkers using the equal-appearing interval scale. The 5-point scale was used to rate each of the variables for each non-native speaker and the interclass correlation coefficients were calculated to identify the most important predictors of foreign accent.

Key words: second language acquisition - pronunciation - factors.

\section{Introduction}

This paper reports research which attempts to identify factors which explain the variance in the second language (L2) phonic competence. The authors investigate the influence and interrelatedness of certain intralingual and paralingual variables, usually considered significant in the foreign language acquisition. The main focus of the study is the level of phonology, i. e. the acquisition of the phonological subsystem of a foreign language. The data collected by empirical research presented in this paper show that, although the influence of some of these variables is doubtless and remarkable, it is not always possible to single out one of them and to disregard the rest of them. Neither is it always possible to say which of these influences will prevail under some circumstances. The acquisition of the phonological system is an immensely complex process, influenced by numerous factors simultaneously. We tried to "capture" the possible influence of several potentially relevant factors, usually intuitively recognised, by professionals and laymen alike, as highly influential.

For the last 40 years, beginning with the classic article of Asher and García [1], the variety of variables influencing the acquisition of the phonological system of a foreign language has been investigated in a large number of experimental studies. Although considerable individual variation can be observed in adults' mastery of $\mathrm{L} 2$ production and perception, the $\mathrm{L} 2$ literature, as well as our common experience as language users, generally indicates that the most adult L2 learners will permanently speak L2 with a foreign accent. One interpretation of this observation is, in the scientific study of the foreign accent, that success in acquiring the phonetics and phonology of a L2 is dependent on a number of factors which influence the performance of individual L2 users. Identifying such factors may be important for the teaching and learning of foreign languages [2]. The studies dealing with the issue published so far differ greatly in terms of the languages, subjects, methods or procedures examined. These differences appear to be responsible for the often divergent results the studies have yielded. The relative importance of many factors is uncertain because many variables relating to subject characteristics tend to be confounded and because of lack of adequate experimental control in some studies.

\section{L2 pronunciation research}

The acquisition of the phonetic/phonological components in the second language is a complex and dynamic process which is influenced by the context and conditions in which the language is learned. The overall quality of L2 pronunciation is likely to vary as a function of the characteristics of the subjects examined. The subjects examined in previous studies differed in a number of potentially important ways. Most of the previous studies examined English as the target $\mathrm{L} 2$ being learned. The native languages spoken by the subjects were far more diverse. The nonnative subjects mostly differed in L2 experience, the age at which they started learning L2, the length of residence in the L2-speaking country, the degree of motivation to speak a L2 and many other variables, [e. g., 3 - 12]. The fact that the subjects examined in previous research differ along the dimensions mentioned above often makes direct comparisons across studies problematic. However, this should not lead one to conclude that the degree of L2 pronunciation accuracy cannot be scaled reliably and validly.

The studies of the overall degree of L2 foreign accent also differ in terms of the techniques used to elicit nonative speech samples. In most studies, subjects have been asked to read words, sentences or paragraphs [e. g., 1, 4 and 8]. In a number of studies, subjects have also been asked to produce samples of free (i. e., extemporaneous) L2 speech [e. g., 13 - 16]. And finally, there

\footnotetext{
* Zdena Kralova ${ }^{1}$, Martin Krajcovic ${ }^{2}$

${ }^{1}$ Department of English Language and Literature, Faculty of Science, University of Zilina, Slovakia, E-mail: zdena.kralova@fpv.uniza.sk;

${ }^{2}$ Department of Industrial Engineering, Faculty of Mechanical Engineering, University of Zilina, Slovakia
} 
have been studies in which subjects were asked to repeat speech materials after hearing a native speaker model in a direct repetition technique [9] or a delayed repetition technique [17]. Some researchers have used more than one elicitation technique [e. g., $13,15,18]$.

In most instances, analyses were carried out to determine if the degree of L2 foreign accent varied as a function of type of elicitation. Both [13] and [15] reported that read speech was judged to be more strongly foreign accented than extemporaneous speech, probably due to differences in the reading ability. The samples of the extemporaneous speech may be problematic, too. This is because they may contain morphosyntactic and lexical errors influencing the ratings. In addition, subjects may be able to avoid difficult L2 sounds or sound sequences. [12] states that more reliable measures may be obtained if raters evaluate a fixed set of materials. However, we consider free speech samples more appropriate for this kind of research as the free speech imitates real communication acts when the speaker concentrates on the content more than on the form of the speech.

A control group of native speakers was recruited in most of the studies cited so far in addition to groups of nonnative subjects. The numbers of raters used in various L2 pronunciation studies differed greatly, ranging from just one [19] to 85 [20]. It is not known at present how many raters are needed to provide a reliable estimate. Unfortunately, not all the studies have included such a control group [21, 22]. This may lead to several problems - for example, it remains uncertain how native speakers would have performed under the specific circumstances of a particular experiment.

One important methodological question pertains to the characteristics of the listeners. In some studies, naive raters were recruited to evaluate speech samples [e. g., 1, 9]. In other studies, "expert" raters such as linguists or teachers participated [e. g., 16, 23]. [15] reported that experienced raters generally perceived a higher degree of $\mathrm{L} 2$ foreign accent in nonnative speech than experienced raters, while [8] found no significant differences between experienced raters and inexperienced raters. In Slovakia it seems rather a problem to recruit a homogeneous group of English native speakers who would be willing to participate in an experiment (often a time consuming one) and who would not be trained or experienced EFL teachers.

The listeners who evaluate the L2 speech usually use a rating scale to indicate the quality of L2 pronunciation they perceive in a speech sample. No standard scale for measuring the accuracy of L2 pronunciation has been developed so far. The equal-appearing interval (EIA) scales differ in resolution. A 5-point scale has been used most commonly [e. g., 8, 13, 14]. [9, 24] employed a continuous scale to evaluate foreign accent. [24] carried out a research to determine whether the foreign accent is a metathetic continuum (a continuum that can be divided into equal intervals ranging from high to low) or a prothetic continuum (a continuum that is not amenable to linear partitioning). They indicated that foreign accentedness is a metathetic continuum, which means that it is appro- priate to use an EAI scale, and found that a 9-point (or 11-point) scale should be used to rate L2 speech samples for the degree of the foreign accent.

\section{Determinants of L2 pronunciation}

The above mentioned differences between studies in design and methodology, have led researchers to draw rather conflicting conclusions about the influence of certain factors on L2 pronunciation. The factors that have received the most attention in literature are undoubtedly the age of L2 learning and the length of stay in a L2-speaking environment. Unfortunately, hardly any study in the existing literature [26] has examined the changes in the degree of L2 pronunciation accuracy in a longitudinal design. Affective and social factors as well as individual aptitude have been seen as possible predictors of the second language phonetic performance [3]. The ability to mimic native speakers and the contact with native speakers have also been reported as having a significant influence on the second language pronunciation [15, 27, 28]. Specific phonetic training has generally been found to be positively associated with the phonetic development in L2. Other factors such as attitudinal and motivational variables have sometimes - though not always - proved to be influential [15].

It seems reasonable to assume that the accuracy with which nonnative speakers pronounce a L2 is, to some extent, dependent on their L1 phonic system. Unfortunately, only a few studies have examined the effect of the L1 background on the degree of L2 foreign accent [e.g., 16, 27, 28]. The authors identified the L1 background as the most important predictor of the foreign accent degree. A few studies have examined the effects of the amount of L1 use on the degree of $\mathrm{L} 2$ foreign accent [17, 29]. The authors conclude that the L1 use patterns exerted a significant negative influence on the degree of L2 foreign accent. However, the subjects in those studies were not matched for other variables, the relative importance of the L1 background therefore remains uncertain.

The language-learning motivation can no longer be treated as a single construct, and it needs to be examined in broad terms including many components. These components include cognitive, affective, and behavioral aspects [30]. [30] identifies and describes the motivational components of learning and success in learning EFL employing statistical methods - the factor analysis data reduction technique using the SPSS program called FACTOR (SPSS inc., 2004). He distinguishes the intrinsic/integrative and extrinsic/instrumental orientation subscales of motives, the latter (esp. the desire to have a higher social status and to get a better job) being found to be a critical component in the L2 learning motivation. Findings from this study revealed that the lower the English proficiency level of students, the lower the degree of their intrinsic motivation.

A thorough literature review showed that motivation has some general effect on L2 pronunciation. [9] identified factors designated "integrative motivation" and "concern for L2 pronunciation" as significant predictors of the L2 pronunciation quality. 
However, the results obtained so far suggest that the strength of concern for the L2 pronunciation accuracy does not automatically lead to perfect L2 speech. [31] hypothesized that a strong correlation will be found between the variable "professional motivation" and the level of L2 pronunciation, but none of his subjects (highly motivated native English teachers of German) received ratings "native-like pronunciation." [13] and [15] found no evidence that motivation affects the degree of $\mathrm{L} 2$ foreign accent. It is important to note that motivation has not been quantified very precisely so far, though different procedures have been used to measure motivational variables. In most cases, the subjects have been asked to rate the importance of good L2 pronunciation for them [e. g., 27, 31]. It is difficult to assess the exact correlation of motivation and L2 pronunciation as many other concomitant variables may be responsible for the results obtained.

Much of the research to date has demonstrated that the age of arrival in a society where the target language is used is the most important factor explaining the variance in the second language phonological competence [e. g., 9, 12, 13, 15, 31]. These results have been used as evidence to support the critical period hypothesis [32, 33]. However, most of these studies concentrated only on immigrant communities. The previous L2 pronunciation research has shown that early learners speak L2 with a lower degree of a foreign accent than late learners. However, no study has yet provided convincing evidence for the claim that $\mathrm{L} 2$ speech will automatically be accent-free if it is learned before the critical period (CP). According to the CP hypothesis, the complete mastery of a L2 is no longer possible if learning begins after the end of the $\mathrm{CP}[6,33]$. A number of researchers have suggested that there may be several CPs, each affecting different linguistic abilities and the first ability to be lost would be the one needed to develop a native-like pronunciation of a L2 [23, 34].

$\mathrm{CP}$ effects have usually been attributed to an age-related loss of neural plasticity or to some sort of neurofunctional reorganization that occurs during the development [e. g., 33 - 36]. A few studies have pointed to what now seems to be a paradoxical effect, that is, better performance by late learners of a L2 [19, 37]. [34] concluded that late learners might have an initial avantage over early learners in $\mathrm{L} 2$ pronunciation ability, albeit an advantage that is only temporary.

It appears that factors other than the age of learning also have an influence on the quality of L2 pronunciation, for example, the chronological age or amount of L1 and L2 use, etc. In many studies, immigrants' speech has been studied and their age of the first exposure to L2 has been indexed as the age at which the subjects first arrived in a L2-speaking country [1, 6, 13, 17, 21]. The results of these L2 foreign accent studies do, in fact, support the view that the earlier in life one learns a L2, the better it will be pronounced. The finding that there is a linear relationship between the age of learning and the degree of L2 foreign accent led both [13] and [34] to suggest that there is a "sensitive" rather than a "critical" period for L2 learning.

Different suggestions have been made as to when the putative critical or sensitive period for L2 speech learning ends: [6] sug- gested the age of 15 years; [38] 12 years; and [34] 6 years of age. The last one has been supported by the results of a number of studies [e.g., 9, 21]. However, a few studies have also shown that the age of L2 learning lower than 6 years does not automatically lead to accent-free L2 speech [e.g., 11, 15] and a number of studies have provided evidence that some L2 learners with age of L2 learning of over 12 years may avoid speaking their $\mathrm{L} 2$ with a detectable foreign accent $[8,31]$.

Not every study has shown a significant effect of the length of stay in a L2-speaking environment on the level of L2 pronunciation. In many studies this variable has been operationalized as the "length of residence", which specifies the number of years spent in a community where L2 is the predominant language. In those studies where a stay (or often residence) effect was found, the stay was a less important predictor of the degree of $\mathrm{L} 2$ foreign accent than the age [e.g., 24]. Studies that have reported an influence of the stay on the L2 speech include [1, 17, 28]. However, there are also several studies that have not found a stay effect [13, 14, 22]. The discrepancies across the studies may be due, in part, to the fact that stay-factor only provides a rough index of the overall L2 experience.

The influence of the language use on L2 pronunciation was first examined by [27] and [28], who asked learners of English to estimate how much time they had spent speaking English with native speakers. In their study of immigrants a composite variable combining years of residence in the USA and a number of months of cohabitation with native speakers was identified as one of the most important predictors of the degree of L2 foreign accent. Three other studies showed no apparent effect of speaking with L2 native speakers on the L2 pronunciation accuracy [15, 22, 24]. [11] claimed that those learners who continue to speak their L1 frequently have significantly stronger foreign accents in L2 than individuals speaking their L1 infrequently do.

Previous research has provided divergent findings concerning the influence of gender on the degree of L2 foreign accent. Some authors [21] identified gender as a significant predictor of the degree of $\mathrm{L} 2$ foreign accent. However, most studies have not identified gender as a significant predictor of the degree of L2 foreign accent [27, 24]. In summary, the results obtained for gender do not lead to any strong conclusions. Some studies reported a significant influence of gender, whereas others did not. The majority of studies that identified gender as a significant predictor of degree of L2 foreign accent found that females usually received higher ratings than males. However, two studies [1,9] suggested that the effect of gender may vary as a function of age of L2 learning and the amount of L2 experience.

\section{Methodology}

Ninety-nine ( 74 female and 25 male) subjects examined in our study are Slovak first-year university students enrolled in the English Language and Literature course. They were approximately at an intermediate level of English proficiency, aged between 18 and 20 
years and had typically started learning English at elementary school with a focus on grammar-based instruction. The majority have never lived in an English-speaking country.

The 5 native English control subjects (3 American - 2 male, 1 female; 2 British - 1 male, 1 female) were asked to auditorily evaluate their pronunciation (English phonic competence - EPC) produced by each of the 99 talkers. They were asked to rate each talker by a mark on a scale from 1 (very poor English pronunciation) to 5 (excellent English pronunciation). The raters were English native speakers more or less experienced in ELT who had lived in Slovakia for several months/years.

The pronunciation samples (a free, extemporaneous talk in English) were recorded and other information was elicited from the participants by the way of tests and questionnaire (Table 2). The L2 background questionnaire asked about personal details, experience and language learning attitudes and beliefs.

Relying on the data most frequently presented in research papers and theoretical discussions, we aimed primarily at investigating the possible influence of factors upon the pronunciation accuracy observed in the interlanguage of learners of English as a foreign language (Table 1). The pronunciation task was recorded on a recorder with a condense microphone. The collection took place in a classroom at the University of Zilina, Slovakia and time allotment was 2 minutes for each student. The data were collected by means of a questionnaire and the tests filled out by each subject after their production of English. The questionnaire contained 18 questions relevant for English as a foreign language. Some of these questions provided facts, some other provided the subject's subjective judgement or opinion. The questionnaires required 30 minutes to complete and the testing time varied according to the variable tested (Table 2)

Native speakers were asked to auditorily evaluate the samples of free English speech produced by each of the non-native talkers using the equal-appearing interval 5-point scale. The 5-point scale was used to rate each of the variables for each non-native speaker (Table 3) and the interclass correlation coefficients (Table 4) were calculated to identify the most important predictors of foreign accent. An average rating was obtained for each speaker and the variable EPC was computed by averaging across each rater's score.

To assess their relative contribution to EPC, the variables were submitted to a simple correlation. Correlation coefficients (r) were calculated for each factor by applying the scoring coefficients generated by the principal component analysis to standardized values for subjects' responses to the questionnaire and test items. The variables were correlated with the total pronunciation rating and were entered into statistical analysis (Table 5).

\section{Results}

Preliminary analysis revealed that much the same EPC ratings were provided by the five raters. The mean for all the native speaker evaluations was 2.93 and there was a standard deviation of 0.73 . Initially, the nine measured variables were correlated with the total pronunciation ratings ( 0.2787 on the 0.05 level). These produced four significant correlations (r) as shown in Table 4:
PsF3 (contact with native speakers of English)
$r=0.3928$
IF1 (English grammatical competence)
$r=0.3723$
$P p F 2$ (self-evaluation of English pronunciation) $\quad r=0.3013$
$P p F 1$ (verbal intelligence in Slovak)
$r=0.2970$

The correlation between EPC and the factors is rather weak The strongest correlation is between EPC - PsF3 and EPC - IF1 which accounted for $15.6 \%$ and $13.9 \%$ variance in the pronunciation ratings obtained by native speakers of English - the coefficient of determination (Table 5). The coefficient of determination (Fig. 1) reveals the percentage of EPC variability which can be explained by the linear relationship with a factor.

\begin{tabular}{|l|l|}
\hline FACTORS OF ENGLISH PHONIC COMPETENCE (EPC) \\
\hline I. Intralingual factors (IF) & II. Paralingual factors (PF) \\
\hline IF1 - English grammatical competence & Psycholingual factors (PpF) \\
\hline IF2 - English metaphonetic competence & $P p F 1$ - verbal intelligence in Slovak \\
\hline IF3 - other foreign languages acquired & $P p F 2$ - self-evaluation of English pronunciation \\
\hline & $P p F 3-$ motivation for English language acquisition \\
\hline & Sociolingual factors (PsF) \\
\hline & $P S F 1$ - age of English language learning \\
\hline & $P S F 2$ - length of stay in an English speaking environment \\
\hline
\end{tabular}

Intralingual factors - characteristics related to a language system

Paralingual factors - temporal characteristics partly related to a language system 


\begin{tabular}{|l|l|l|}
\hline FACTOR & Abbr. & Testing method \\
\hline English grammatical competence & IF1 & $\begin{array}{l}\text { Quick Placement Test Trial Version 2A } \\
\text { (University of Cambridge) }\end{array}$ \\
\hline English metaphonetic competence & IF2 & English Phonetics and Phonology Test (Z. Kralova) \\
\hline other foreign languages acquired & IF3 & Language Background Questionnaire (Z. Kralova) \\
\hline verbal intelligence in Slovak & $\mathrm{PpF} 1$ & Psychological Clinics Standard (Slovak Republic) \\
\hline self-evaluation of English pronunciation & $\mathrm{PpF} 2$ & Language Background Questionnaire (Z. Kralova) \\
\hline motivation for English language acquisition & $\mathrm{PpF} 3$ & Language Background Questionnaire (Z. Kralova) \\
\hline age of English language learning & $\mathrm{PsF1}$ & Language Background Questionnaire (Z. Kralova) \\
\hline length of stay in an English speaking environment & $\mathrm{PsF} 2$ & Language Background Questionnaire (Z. Kralova) \\
\hline contact with native speakers of English & $\mathrm{PsF3}$ & Language Background Questionnaire (Z. Kralova) \\
\hline
\end{tabular}

\begin{tabular}{|l|l|l|l|l|l|}
\hline EVALUATION SCALE & $\mathbf{4}$ & $\mathbf{3}$ & $\mathbf{2}$ & $\mathbf{1}$ \\
\hline & $\mathbf{5}$ & very good & good & average & poor \\
\hline EPC & excellent & $56-43$ & $42-29$ & $28-15$ & $14-0$ \\
\hline IF1 & $70-57$ & $32-25$ & $24-17$ & $16-9$ & $8-0$ \\
\hline IF2 & $40-33$ & 1 Germanic & 1 non-Slavic/non-Germanic & 1 Slavic & none \\
\hline IF3 & more languages & $144-131$ & $130-116$ & $115-86$ & $85-71$ \\
\hline PpF1 & $\geq 145$ & very good & good & average & poor \\
\hline PpF2 & excellent & internal & external & indefinite & none \\
\hline PpF3 & combined & $7-10$ years & $11-14$ years & $15-18$ years & $\geq 19$ years \\
\hline PsF1 & $1-6$ years & month/s & week/s & day/s & none \\
\hline PsF2 & year/s & weekly & monthly & yearly & none \\
\hline PsF3 & daily & &
\end{tabular}

\begin{tabular}{|c|c|c|c|c|c|c|c|c|c|c|}
\hline \multirow{3}{*}{ Student } & \multirow{3}{*}{ EPC } & \multirow{2}{*}{\multicolumn{3}{|c|}{ Intralingual factors }} & \multicolumn{6}{|c|}{ Paralingual factors } \\
\hline & & & & & \multicolumn{3}{|c|}{ Psycholingual factors } & \multicolumn{3}{|c|}{ Sociolingual factors } \\
\hline & & IF1 & IF2 & IF3 & PpF1 & $\mathrm{PpF} 2$ & $\mathrm{PpF3}$ & PsF1 & PsF2 & PsF3 \\
\hline 1 & 4 & 3 & 3 & 4 & 5 & 3 & 3 & 4 & 4 & 4 \\
\hline 2 & 4 & 4 & 4 & 4 & 2 & 4 & 3 & 4 & 1 & 5 \\
\hline 3 & 2 & 3 & 2 & 4 & 2 & 2 & 4 & 4 & 1 & 1 \\
\hline 4 & 3 & 4 & 3 & 3 & 4 & 3 & 3 & 3 & 1 & 2 \\
\hline 5 & 3 & 3 & 3 & 4 & 5 & 3 & 3 & 2 & 1 & 3 \\
\hline 6 & 1 & 3 & 2 & 4 & 3 & 3 & 3 & 3 & 1 & 1 \\
\hline 7 & 3 & 3 & 3 & 4 & 4 & 3 & 4 & 4 & 1 & 1 \\
\hline 8 & 3 & 4 & 3 & 5 & 2 & 4 & 3 & 3 & 1 & 5 \\
\hline 9 & 2 & 3 & 3 & 4 & 4 & 3 & 3 & 3 & 1 & 2 \\
\hline 10 & 3 & 3 & 2 & 4 & 4 & 2 & 3 & 4 & 5 & 4 \\
\hline 11 & 3 & 4 & 3 & 4 & 5 & 4 & 3 & 4 & 1 & 1 \\
\hline 12 & 4 & 4 & 3 & 4 & 4 & 4 & 3 & 4 & 3 & 5 \\
\hline 13 & 2 & 2 & 2 & 1 & 3 & 3 & 2 & 3 & 1 & 1 \\
\hline 14 & 2 & 3 & 2 & 4 & 4 & 3 & 3 & 3 & 1 & 3 \\
\hline 15 & 2 & 3 & 2 & 3 & 3 & 3 & 3 & 4 & 1 & 1 \\
\hline 16 & 3 & 2 & 3 & 4 & 3 & 4 & 3 & 4 & 1 & 3 \\
\hline 17 & 2 & 3 & 2 & 4 & 3 & 3 & 4 & 4 & 1 & 1 \\
\hline 18 & 3 & 3 & 3 & 3 & 2 & 3 & 3 & 3 & 4 & 4 \\
\hline
\end{tabular}




\begin{tabular}{|c|c|c|c|c|c|c|c|c|c|c|}
\hline \multirow{3}{*}{ Student } & \multirow{3}{*}{ EPC } & \multirow{2}{*}{\multicolumn{3}{|c|}{ Intralingual factors }} & \multicolumn{6}{|c|}{ Paralingual factors } \\
\hline & & & & & \multicolumn{3}{|c|}{ Psycholingual factors } & \multicolumn{3}{|c|}{ Sociolingual factors } \\
\hline & & IF1 & IF2 & IF3 & PpF1 & $\mathrm{PpF} 2$ & $\mathrm{PpF3}$ & PsF1 & PsF2 & PsF3 \\
\hline 19 & 2 & 3 & 3 & 2 & 3 & 3 & 4 & 4 & 1 & 1 \\
\hline 20 & 3 & 3 & 3 & 1 & 4 & 4 & 2 & 4 & 1 & 1 \\
\hline 21 & 2 & 4 & 3 & 2 & 2 & 2 & 4 & 3 & 5 & 4 \\
\hline 22 & 3 & 3 & 2 & 4 & 4 & 3 & 5 & 4 & 1 & 1 \\
\hline 23 & 3 & 3 & 3 & 5 & 3 & 4 & 4 & 3 & 1 & 3 \\
\hline 24 & 3 & 3 & 3 & 3 & 4 & 3 & 4 & 4 & 1 & 1 \\
\hline 25 & 2 & 3 & 2 & 4 & 3 & 4 & 2 & 3 & 1 & 1 \\
\hline 26 & 4 & 3 & 3 & 3 & 4 & 3 & 2 & 3 & 4 & 4 \\
\hline 27 & 3 & 4 & 3 & 4 & 4 & 3 & 3 & 4 & 1 & 1 \\
\hline 28 & 3 & 3 & 3 & 2 & 4 & 3 & 3 & 4 & 4 & 4 \\
\hline 29 & 3 & 3 & 3 & 4 & 4 & 3 & 4 & 4 & 5 & 5 \\
\hline 30 & 2 & 4 & 3 & 5 & 3 & 2 & 2 & 3 & 1 & 4 \\
\hline 31 & 3 & 4 & 2 & 4 & 4 & 5 & 4 & 3 & 1 & 1 \\
\hline 32 & 3 & 3 & 3 & 2 & 3 & 3 & 3 & 4 & 1 & 1 \\
\hline 33 & 2 & 3 & 2 & 3 & 4 & 3 & 3 & 3 & 3 & 2 \\
\hline 34 & 3 & 3 & 3 & 4 & 3 & 4 & 4 & 4 & 1 & 1 \\
\hline 35 & 5 & 5 & 2 & 5 & 4 & 4 & 3 & 4 & 1 & 3 \\
\hline 36 & 1 & 3 & 2 & 4 & 1 & 4 & 3 & 3 & 1 & 1 \\
\hline 37 & 2 & 3 & 3 & 5 & 4 & 3 & 4 & 4 & 1 & 3 \\
\hline 38 & 2 & 3 & 3 & 1 & 2 & 3 & 3 & 3 & 1 & 1 \\
\hline 39 & 3 & 3 & 2 & 4 & 5 & 4 & 3 & 4 & 4 & 4 \\
\hline 40 & 2 & 3 & 2 & 4 & 5 & 4 & 3 & 4 & 1 & 1 \\
\hline 41 & 3 & 3 & 3 & 2 & 2 & 3 & 2 & 4 & 4 & 4 \\
\hline 42 & 2 & 3 & 3 & 4 & 3 & 3 & 3 & 4 & 1 & 1 \\
\hline 43 & 4 & 3 & 2 & 4 & 4 & 4 & 4 & 4 & 5 & 5 \\
\hline 44 & 4 & 3 & 3 & 4 & 5 & 4 & 3 & 1 & 2 & 2 \\
\hline 45 & 2 & 3 & 2 & 4 & 4 & 3 & 3 & 4 & 1 & 1 \\
\hline 46 & 3 & 3 & 2 & 4 & 5 & 3 & 2 & 3 & 4 & 4 \\
\hline 47 & 3 & 4 & 5 & 4 & 5 & 3 & 4 & 3 & 4 & 3 \\
\hline 48 & 3 & 3 & 3 & 4 & 3 & 3 & 5 & 2 & 1 & 1 \\
\hline 49 & 3 & 3 & 3 & 3 & 4 & 3 & 2 & 4 & 1 & 1 \\
\hline 50 & 4 & 4 & 4 & 4 & 4 & 3 & 3 & 4 & 1 & 1 \\
\hline 51 & 3 & 3 & 2 & 4 & 4 & 3 & 4 & 3 & 1 & 3 \\
\hline 52 & 3 & 4 & 3 & 1 & 4 & 4 & 1 & 3 & 1 & 1 \\
\hline 53 & 3 & 3 & 2 & 3 & 2 & 2 & 3 & 4 & 1 & 1 \\
\hline 54 & 5 & 4 & 3 & 4 & 4 & 4 & 4 & 4 & 5 & 5 \\
\hline 55 & 3 & 3 & 3 & 4 & 4 & 3 & 3 & 4 & 1 & 1 \\
\hline 56 & 2 & 3 & 3 & 4 & 3 & 3 & 4 & 3 & 1 & 1 \\
\hline 57 & 3 & 4 & 2 & 4 & 4 & 3 & 3 & 4 & 1 & 1 \\
\hline 58 & 3 & 3 & 3 & 4 & 4 & 3 & 3 & 2 & 1 & 2 \\
\hline 59 & 3 & 4 & 3 & 3 & 4 & 3 & 4 & 4 & 4 & 3 \\
\hline 60 & 3 & 3 & 3 & 4 & 4 & 2 & 5 & 4 & 1 & 3 \\
\hline 61 & 3 & 3 & 3 & 4 & 5 & 3 & 3 & 4 & 1 & 1 \\
\hline 62 & 3 & 4 & 3 & 4 & 4 & 3 & 2 & 4 & 1 & 1 \\
\hline 63 & 4 & 4 & 3 & 4 & 3 & 3 & 4 & 4 & 1 & 2 \\
\hline 64 & 3 & 3 & 2 & 4 & 4 & 3 & 3 & 4 & 1 & 1 \\
\hline 65 & 2 & 3 & 2 & 5 & 4 & 3 & 3 & 3 & 1 & 1 \\
\hline 66 & 3 & 4 & 3 & 5 & 3 & 3 & 4 & 4 & 1 & 2 \\
\hline 67 & 3 & 2 & 2 & 4 & 4 & 2 & 4 & 4 & 1 & 1 \\
\hline 68 & 3 & 4 & 3 & 3 & 4 & 3 & 3 & 4 & 3 & 1 \\
\hline 69 & 3 & 3 & 2 & 3 & 4 & 3 & 3 & 4 & 1 & 3 \\
\hline
\end{tabular}




\begin{tabular}{|c|c|c|c|c|c|c|c|c|c|c|}
\hline \multirow{3}{*}{ Student } & \multirow{3}{*}{ EPC } & \multirow{2}{*}{\multicolumn{3}{|c|}{ Intralingual factors }} & \multicolumn{6}{|c|}{ Paralingual factors } \\
\hline & & & & & \multicolumn{3}{|c|}{ Psycholingual factors } & \multicolumn{3}{|c|}{ Sociolingual factors } \\
\hline & & IF1 & IF2 & IF3 & PpF1 & $\mathrm{PpF} 2$ & PpF3 & PsF1 & PsF2 & PsF3 \\
\hline 70 & 2 & 3 & 3 & 4 & 4 & 3 & 4 & 4 & 1 & 1 \\
\hline 71 & 3 & 3 & 3 & 3 & 4 & 4 & 3 & 4 & 4 & 4 \\
\hline 72 & 4 & 3 & 3 & 1 & 4 & 3 & 4 & 4 & 5 & 4 \\
\hline 73 & 3 & 3 & 2 & 4 & 3 & 2 & 3 & 4 & 1 & 3 \\
\hline 74 & 3 & 3 & 3 & 4 & 5 & 3 & 3 & 4 & 1 & 1 \\
\hline 75 & 4 & 3 & 4 & 4 & 4 & 4 & 4 & 3 & 1 & 1 \\
\hline 76 & 3 & 3 & 3 & 5 & 3 & 2 & 4 & 3 & 1 & 2 \\
\hline 77 & 3 & 3 & 3 & 4 & 4 & 3 & 2 & 4 & 3 & 3 \\
\hline 78 & 3 & 4 & 2 & 4 & 4 & 4 & 3 & 2 & 1 & 2 \\
\hline 79 & 4 & 3 & 3 & 5 & 5 & 4 & 3 & 4 & 2 & 4 \\
\hline 80 & 3 & 3 & 3 & 3 & 4 & 3 & 3 & 4 & 1 & 1 \\
\hline 81 & 4 & 3 & 3 & 3 & 5 & 3 & 4 & 4 & 1 & 3 \\
\hline 82 & 3 & 4 & 2 & 1 & 5 & 4 & 4 & 4 & 1 & 1 \\
\hline 83 & 3 & 3 & 2 & 1 & 4 & 2 & 3 & 3 & 1 & 1 \\
\hline 84 & 3 & 3 & 2 & 4 & 3 & 3 & 3 & 4 & 4 & 3 \\
\hline 85 & 3 & 4 & 2 & 4 & 3 & 3 & 3 & 3 & 1 & 1 \\
\hline 86 & 3 & 3 & 2 & 2 & 3 & 2 & 3 & 4 & 1 & 2 \\
\hline 87 & 4 & 3 & 3 & 5 & 3 & 3 & 5 & 4 & 1 & 1 \\
\hline 88 & 2 & 2 & 3 & 5 & 5 & 2 & 3 & 2 & 1 & 1 \\
\hline 89 & 4 & 4 & 2 & 4 & 3 & 4 & 3 & 2 & 1 & 1 \\
\hline 90 & 2 & 3 & 2 & 3 & 1 & 2 & 1 & 4 & 1 & 1 \\
\hline 91 & 3 & 3 & 3 & 3 & 4 & 4 & 1 & 3 & 4 & 3 \\
\hline 92 & 3 & 4 & 3 & 3 & 4 & 4 & 5 & 3 & 4 & 3 \\
\hline 93 & 3 & 3 & 2 & 4 & 3 & 4 & 4 & 4 & 1 & 1 \\
\hline 94 & 2 & 2 & 2 & 4 & 4 & 3 & 3 & 4 & 1 & 1 \\
\hline 95 & 4 & 4 & 2 & 5 & 4 & 4 & 4 & 4 & 1 & 3 \\
\hline 96 & 3 & 3 & 3 & 1 & 3 & 3 & 3 & 3 & 5 & 5 \\
\hline 97 & 3 & 3 & 3 & 5 & 4 & 4 & 4 & 2 & 1 & 1 \\
\hline 98 & 3 & 3 & 2 & 5 & 5 & 3 & 4 & 1 & 1 & 3 \\
\hline 99 & 3 & 3 & 3 & 4 & 3 & 4 & 3 & 4 & 4 & 3 \\
\hline Mean & 2.93 & 3.22 & 2.67 & 3.61 & 3.61 & 3.18 & 3.24 & 3.51 & 1.81 & 2.20 \\
\hline $\mathbf{r}$ & - & 0.3723 & 0.2761 & 0.0815 & 0.2970 & 0.3013 & 0.1475 & 0.1072 & 0.2559 & 0.3928 \\
\hline
\end{tabular}

Statistical analysis

Table 5

\begin{tabular}{|l|c|c|c|c|c|c|c|c|c|c|}
\hline & EPC & IF1 & IF2 & IF3 & PpF1 & PpF2 & PpF3 & PsF1 & PsF2 & PsF3 \\
\hline Mean & 2.93 & 3.22 & 2.67 & 3.61 & 3.61 & 3.18 & 3.24 & 3.51 & 1.81 & 2.20 \\
\hline Modus & 3 & 3 & 3 & 4 & 4 & 3 & 3 & 4 & 1 & 1 \\
\hline Median & 3 & 3 & 3 & 4 & 4 & 3 & 3 & 4 & 1 & 2 \\
\hline Standard deviation & 0.7282 & 0.5422 & 0.5860 & 1.0619 & 0.9408 & 0.6569 & 0.8176 & 0.7159 & 1.3902 & 1.3482 \\
\hline Coefficient of variation & $24.86 \%$ & $16.83 \%$ & $21.98 \%$ & $29.45 \%$ & $26.09 \%$ & $20.65 \%$ & $25.22 \%$ & $20.43 \%$ & $76.89 \%$ & $61.23 \%$ \\
\hline Covariance & & 0.1470 & 0.1178 & 0.0630 & 0.2044 & 0.1441 & 0.0878 & 0.0559 & 0.2591 & 0.3880 \\
\hline Correlation coefficient & & 0.3723 & 0.2761 & 0.0815 & 0.2970 & 0.3013 & 0.1475 & 0.1072 & 0.2559 & 0.3928 \\
\hline Coefficient of determination & & $\mathbf{0 . 1 3 8 6}$ & 0.0762 & 0.0066 & 0.0890 & 0.0908 & 0.0217 & 0.0114 & 0.0655 & $\mathbf{0 . 1 5 6 1}$ \\
\hline
\end{tabular}

\section{Conclusion}

The study assessed the relation between the overall degree of the perceived foreign accent in non-natives' English speech and a variety of intralingual and paralingual factors claimed to affect the $\mathrm{L} 2$ pronunciation. The empirical data clearly indicated that the so-called foreign accent phenomenon is a highly complex one. Namely, it is not always possible to detect a clear correlation 


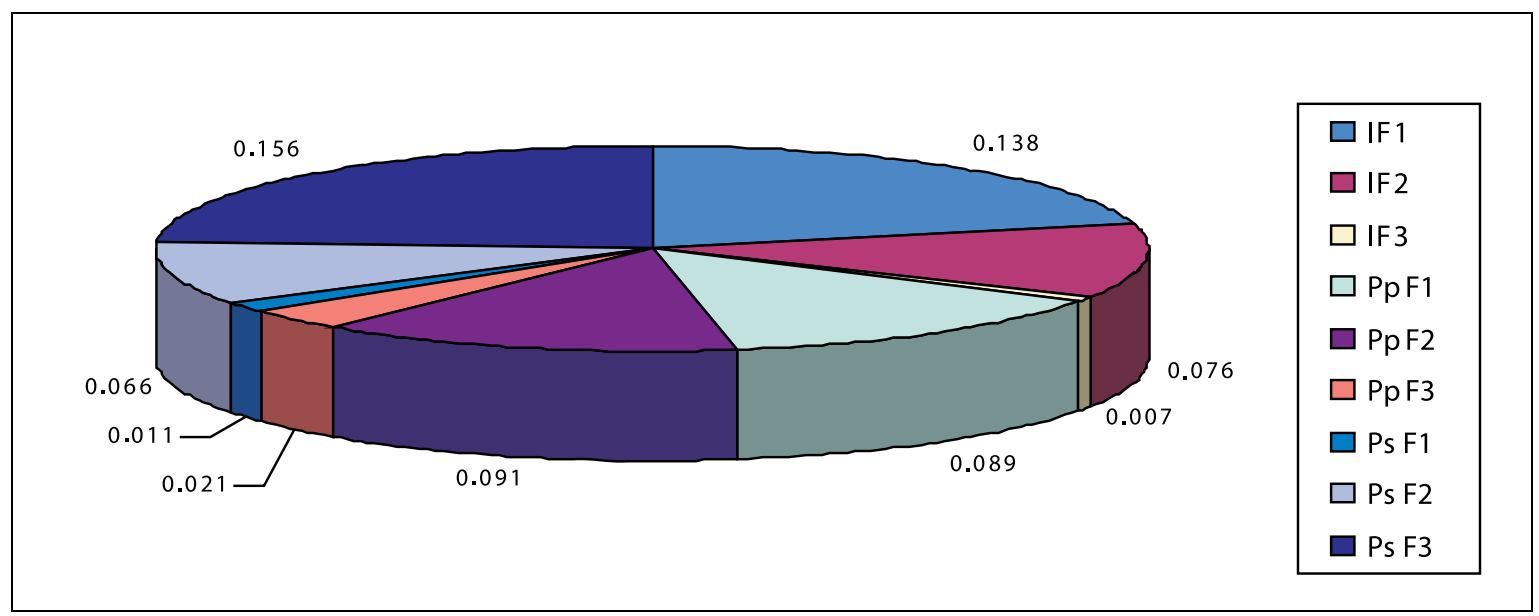

Fig. 1 Coefficients of determination

between the observed level of phonic performance of a foreign language learner and any of the factors usually considered crucial for the reduction of a foreign accent. Thus it is not always possible to isolate those variables which should be considered the most important, nor is it always possible to pin down the exact way in which a particular variable exerts its influence on the process of L2 acquisition. The analysis showed that the mutual influence of a number of factors is so complex that the influence of each and every one of them cannot be singled out and analysed independently, without taking into consideration all the others.

The results show that none of the factors proved crucial for the differences in the foreign language pronunciation rating and no statistically significant correlation could be established between the most of the variables. A statistically significant correlation ( 0.2787 on the 0.05 level) is an argument for the conclusion that only four of the analysed variables may be considered significant in the foreign language acquisition:

\section{PsF3 (contact with native speakers of English), IF1 (English grammatical competence), PpF2 (self-evaluation of English pronunciation), PpF1 (verbal intelligence in Slovak)}

Note, however, that longitudinal research is needed to determine more precisely at what point in L2 learning, if any, the individual factors cease to have an ameliorative effect on the pronunciation of L2. Although it is not always possible to discern the exact way in which some of these variables exert the influence on the linguistic behaviour of the learner, they must always be taken into account when analysing the process of language acquisition at all linguistic levels, but at the level of phonetics in particular. The identification of aspects that influence the overall L2 pronunciation accuracy may be important for teaching and learning second languages.

\section{References}

[1] ASHER, J. J., GARCIA, R. (1969):. The Optimal Age to Learn a Second Language. The Modern Language Journal, n. 53, pp. 334-341.

[2] HLAVNOVA, A. (1999): Language as Means of Communication. Communications - Scientific Letters of University of Zilina, n. 1, pp. 90-93.

[3] FLEGE, J. E. (1987): A Critical Period for Learning to Pronounce Foreign Languages. Applied Linguistics, n. 8, pp. 162-177.

[4] FLEGE, J. E. (1988): Factors Affecting Degree of Perceived Foreign Accent in English Sentences. Journal of the Acoustical Society of America, n. 84, pp. 70-79.

[5] SINGLETON, D. (1989): Language Acquistion: the Age Factor. Multilingual Matters. Clevedon: Avon.

[6] PATKOWSKI, M. S. (1990): Age and Accent in a Second Language. Reply to James Emil Flege. Applied Linguistics, n. 11, pp. 73-89.

[7] FLEGE, J. E. (1991): Perception and Production: the Relevance of Phonetic Input to L2 Phonological Learning. In: Crosscurrents in Second Language Acquisition. T. Heubner - C. A. Ferguson (eds.), Amsterdam.

[8] BONGAERTS, T., VAN SUMMEREN, C., PLANKEN, B., SCHILS, E. (1997): Age and Ultimate Attainment in the Pronunciation of a Foreign Language. Studies in Second Language Acquisition, n. 19, pp. 447-465.

[9] FLEGE, J. E., MUNRO, M. J., MACKAY, I. R. A. (1995): Factors Affecting Strength of Perceived Foreign Accent in a Second Language. Journal of the Acoustical Society of America, n. 97, pp. 3125-3134.

[10] BIALYSTOCK, E. (1997): The Structure of Age: in Search of Barriers to SLA. Second Language Research, n. 2, pp. 116-137. 
[11] FLEGE, J. E., FRIEDA, E. M., NOZAWA, T. (1997): Amount of Native-language (L1) Use Affects the Pronunciation of an L2. Journal of Phonetics, n. 25, pp. 169-186.

[12] PISKE, T., MACKAY, I. R. A., FLEGE, J. E. (2001): Factors Affecting Degree of Foreign Accent in an L2: a Review. Journal of Phonetics, n. 29, pp. 191-215.

[13] OYAMA, S. (1976): The Sensitive Period for the Acquisition of a Nonnative Phonological System. Journal of Psycholinguistic Research, n. 5, pp. 261-283.

[14] PIPER, T.: CANSIN, D. (1988): Factors Influencing the Foreign Accent. The Canadian Modern Language Review, n. 44, pp. $334-342$.

[15] THOMPSON, I. (1991): Foreign Accents Revisited: the English Pronunciation of Russian Immigrants. Language Learning, n. 41, pp. 177-204.

[16] KRALOVA, Z. (2005): Slovak-English Phonic Interference (in Slovak). Zilina, Fakulta prirodnych vied Zilinskej univerzity v Ziline.

[17] FLEGE, J. E., YENI-KOMSHIAN, G., LIU, H. (1999): Age Constraints on Second Language Acquisition. Journal of Memory and Language, n. 41, pp. 78-104.

[18] MARKHAM, D. (1997): Phonetic Imitation, Accent, and the Learner. Lund: Lund University Press.

[19] SNOW, C. E., HOEFNAGEL-HÖHLE, M. (1977): Age Differences in the Pronunciation of Foreign Sounds. Language and Speech, n. 20 , pp. $357-365$.

[20] NEUFELD, G. G. (1979): Towards a Theory of Language Learning Ability. Language Learning, n. 29, pp. 227-241.

[21] TAHTA, S., WOOD, M., LOEWENTHAL, K. (1981): Foreign Accents: Factors Relating to Transfer of Accent from the First Language to a Second Language. Language and Speech, n. 24, pp. 265-272.

[22] ELLIOTT, R. E. (1995): Field Independence/Dependence, Hemispheric Specialization, and Attitude in Relation to Pronunciation Accuracy in Spanish as a Foreign Language. The Modern Language Journal, n. 79, pp. 356-371.

[23] FATHMAN, A. (1975): The Relationship Between Age and Second Language Productive Ability. Language Learning, n. 25, pp. 245-253.

[24] FLEGE, J. E., FLETCHER, K. L. (1992): Talker and Listener Effects on Degree of Perceived Foreign Accent. Journal of the Acoustical Society of America, n. 91, pp. 370-389.

[25] SOUTHWOOD, M. H., FLEGE, J. E. (1999). Scaling Foreign Accent: Direct Magnitude Estimation Versus Interval Scaling. Clinical Linguistics and Phonetics, n. 13, pp. 335-449.

[26] MEADOR, D., FLEGE, J. E., MACKAY, I. R. A. (2000): Factors Affecting the Recognition of Words in a Second Language. Bilingualism: Language and Cognition, n. 3, pp. 55-67.

[27] SUTER, R. W. (1976): Predictors of pronunciation accuracy in second language learning. Language Learning, n. 26, pp. 233-253.

[28] PURCELL, E. T., SUTER, R. W. (1980): Predictors of Pronunciation Accuracy: A Reexamination. Language Learning, n. 30, pp. 271-187.

[29] GUION, S. G., FLEGE, J. E., LOFTIN, J. D. (2000): The Effect of L1 Use on Pronunciation of Quichua-Spanish Bilinguals. Journal of Phonetics, n. 28, pp. 27-42.

[30] SEMMAR, Y. (2006): An Exploratory Study of Motivational Variables in a Foreign Language Learning Context. Journal of Language and Learning, n. 1, pp. 118-132.

[31] MOYER, A. (1999): Ultimate Attainment in L2 Phonology. Studies in Second Language Acquisition, n. 21, pp. 81-108.

[32] PENFIELD, W., ROBERTS, L. (1959): Speech and Brain Mechanisms. Princeton: Princeton University Press.

[33] LENNEBERG, E. H. (1967): The Biological Foundations of Language. New York: Wiley.

[34] LONG, M. H. (1990): Maturational Constraints on Language Development. Studies in Second Language Acquisition, n. 12, pp. 251-285.

[35] LAMENDELlA, J. T. (1977): General Principles of Neurofunctional Organization and their Manifestation in Primary and Nonprimary Language Acquisition. Language Learning, n. 27, pp. 155-196.

[36] NEVILLE, H. J., MILLS, D. L., LAWSON, D. S. (1992): Fractionating Language: Different Neural Subsystems with Different Sensitive Periods. Cerebral Cortex, n. 2, pp. 244-258.

[37] OLSON, L. L., SAMUELS, S. J. (1973): The Relationship Between Age and Accuracy of Foreign Language Pronunciation. Journal of Educational Research, n. 66, pp. 263-268.

[38] SCOVEL, T. (1988): A Time to Speak: a Psycholinguistic Inquiry into the Critical Period from Human Speech. New York: Newbury House/Harper and Row. 